\title{
Power Flow Simulation of DC Railway Power Supply Systems with Regenerative Braking
}

\author{
Fulin Fan \\ Dept. Electronic and Electrical Engineering \\ University of Strathclyde \\ Glasgow, United Kingdom \\ f.fan@strath.ac.uk
}

\author{
Brian G. Stewart \\ Dept. Electronic and Electrical Engineering \\ University of Strathclyde \\ Glasgow, United Kingdom \\ brian.stewart.100@strath.ac.uk
}

\begin{abstract}
The energy efficiency of a railway electrification system can be improved by the recovery of regenerative braking energy which is converted from the mechanical energy of braking trains. In a direct current (DC) railway power supply system, the regenerated energy which would otherwise be dissipated as heat in braking resistors may be consumed by surrounding accelerating trains, stored by energy storage systems, or fed back to upstream alternative current (AC) sides via reversible substations (RSS). It is necessary to evaluate the benefits related to energy savings achieved by the installation of RSS due to the high cost of initial investment. This paper models DC railway power supply systems in Simulink to simulate power flows within the systems in different scenarios with or without the deployment of RSS. Pantograph voltages of trains and power exchange between $\mathrm{AC}$ and $\mathrm{DC}$ sides are analysed to illustrate the effectiveness of the developed models and the limits on the braking energy recovery.
\end{abstract}

Keywords-DC railway power supply system, power exchange, power flow simulation, regenerative braking, reversible substation

\section{INTRODUCTION}

Increasing the energy efficiency of the European railway systems is required to achieve the target of cutting $30 \%$ of their specific final energy consumption and $50 \%$ of average $\mathrm{CO}_{2}$ emissions from train operation by 2030 compared to the 1990 base year [1]. Most strategies related to the improvement of the energy efficiency of a direct current (DC) railway system focus on an efficient management of the regenerative braking energy [2] which is converted from the mechanical energy of a braking train through reversing the operation of its motors [3]. The regenerated energy can supply the train's onboard auxiliary loads while the surplus energy could be partially or completely delivered to nearby cruising or accelerating trains via a third rail or an overhead line (OHL). The excess energy which cannot be recaptured is dissipated as heat in onboard dumping resistors so as to avoid the exceedance of the OHL's over-voltage limit [3].

The recovery of the regenerative braking energy can be improved by optimising timetables so as to synchronise the acceleration and deceleration of trains [4]. Furthermore, the deployment of wayside or onboard energy storage systems can increase the use of braking energy by storing the excess energy and putting it onto the system when needed [5]. An alternative solution is the installation of reversible substations (RSS) [6] which allow the braking energy to be fed back to the upstream alternative current (AC) side and used by AC equipment in RSS or sold back to electricity suppliers depending on the local legislations and rules of electrical grids $[2,7]$. Though having a number of advantages over energy

The research was developed in the framework of 16ENG04 MyRails Project which received funding from the EMPIR programme co-financed by the Participating States and from the European Union's Horizon 2020 Research and Innovation Programme. storage, e.g. fewer AC/DC conversion losses and lower safety constraints [7], the costly investment on RSS may slow-pace the deployment of RSS. It is therefore necessary to model the power exchange between AC and DC sides so as to quantify the benefit associated with the energy saving achieved by using RSS to recover the braking energy.

Some research related to the simulation of power flows in a railway power supply system models a train by a controlled current source [8-10], and a unidirectional substation (USS) by a DC voltage source connected in series with a diode $[8,9]$ or a three-phase AC voltage source combined with a rectifier [10]. Based on these research, this paper additionally models the paths enabling the delivery of the regenerated energy back to AC sides. The railway system models are developed in Matlab/Simulink [11] to simulate four presumed scenarios where one/two trains move along a railway line supplied by two USS/RSS. The simulated pantograph voltages and power supplied to the DC railway system or fed-back-to AC sides via substations are analysed to illustrate the model effectiveness.

The models are developed here in the context of a $3 \mathrm{kV}$ DC railway line between Pisa and Collesalvetti which is supplied by two substations (SS) separated by $20 \mathrm{~km}$ [12], as shown in Fig. 1. The paper is structured as follows: Section II describes mathematical calculations of a train's position and consumed/ regenerated power based on train characteristics; Section III develops simulation models of railway power supply systems for the presumed scenarios; Section IV analyses the simulated pantograph voltages and power exchange between $\mathrm{AC}$ and DC sides; Section V presents conclusions and future work.

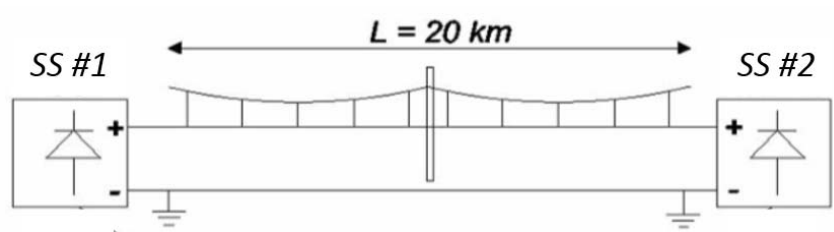

Fig. 1. A 3kV DC railway line supplied by two substations (SS) [12].

\section{CAlculation of Train Position AND POWER}

\section{A. Train Position Calculation}

The train position defined here as its distance from SS\#1 is necessary to simulate the variable resistances of OHL sections between SS and trains and between two neighbouring trains. The position $(\mathrm{km})$ of a train moving away from SS\#1 is calculated as the sum of its initial position $(\mathrm{km})$ and the integral of its speed $(\mathrm{m} / \mathrm{s})$ over time $(s)$. Fig. 2 shows the presumed speeds and calculated positions of two trains (i.e. Train\#1 and Train\#2) which are initially $5 \mathrm{~km}$ and $10 \mathrm{~km}$ away from SS\#1 respectively. Since the paper focuses on the model effectiveness, the railway system models are simulated for a short period of 65 s only where the deceleration of Train\# 1 is synchronised with the acceleration of Train $\# 2$ over the last $25 \mathrm{~s}$. 

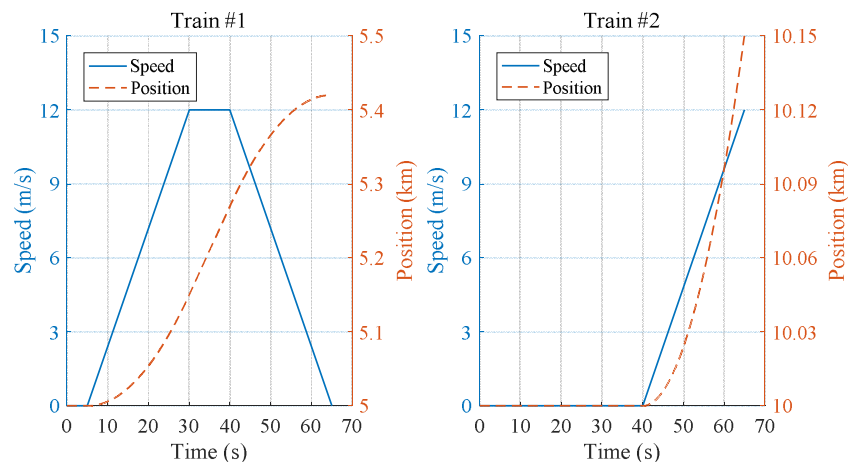

Fig. 2. Presumed speeds $(\mathrm{m} / \mathrm{s})$ and calculated positions $(\mathrm{km})$ of Train\#1 and Train\#2 over $65 \mathrm{~s}$.

\section{B. Train Power Calculation}

The power consumption or regeneration of a train moving on an inclined rail surface as shown in Fig. 3 mainly depends on its speed $v$ and tractive force $F_{t r}$. According to Newton's second law of motion, the latter is calculated from the train's effective mass $M_{\text {eff }}(\mathrm{kg})$ and the rate of change of $v$ [13]:

$$
F_{\text {tr }}=M_{\text {eff }} \cdot(d v / d t)+\left(F_{r r}+F_{\text {aero }}+F_{\text {grad }}\right)
$$

where terms $F_{r r}, F_{\text {aero }}$ and $F_{\text {grad }}$ denote the rolling resistance force, aerodynamic drag force and gradient force of the train. Some research estimates the sum of $F_{r r}$ and $F_{\text {aero }}$ (i.e. referred to as the frictional drag force [14]) by an empirical $3^{\text {rd }}$-order polynomial of $v$, known as the Davis equation $[9,14$, $15]$. This paper models $F_{r r}, F_{\text {aero }}$ and $F_{\text {grad }}$ separately [10, 13]:

$$
\begin{aligned}
& F_{r r}=c_{r r} \cdot M_{e f f} \cdot g \cdot \cos \alpha \\
& F_{\text {aero }}=c_{a} \cdot \rho_{a} \cdot A_{F} \cdot v^{2} / 2 \\
& F_{\text {grad }}=M_{\text {eff }} \cdot g \cdot \sin ( \pm \alpha)
\end{aligned}
$$

where $c_{r r}$ and $c_{a}$ are coefficients related to $F_{r r}$ and $F_{a e r o} ; g$ is the gravitational acceleration $(\mathrm{N} / \mathrm{kg}) ; \alpha$ is the angle of slope; $\rho_{a}$ is the air density $\left(\mathrm{kg} / \mathrm{m}^{3}\right)$; and $A_{F}$ is the projected frontal area of the train $\left(\mathrm{m}^{2}\right)$. Positive and negative signs in Eq. (4) are for uphill and downhill respectively. $M_{\text {eff }}$ consists of passenger mass $M_{p}$ and rolling stock mass $M_{s}$ and models the rotational inertia effect by a rotary allowance $\lambda_{r}[14]$ :

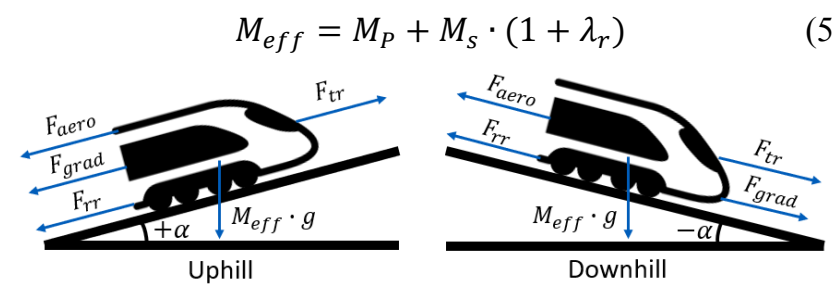

Fig. 3. Forces applied to a train on an inclined surface.

The train's instantaneous mechanical power is the product of $F_{t r}$ and $v$. Mechanical and electrical energy cannot be fully converted into each other due to energy losses in the train's converters, motors and gearboxes, etc. [10]. Given efficiencies of converters, motors and gearboxes denoted by $\eta_{c}, \eta_{m}$ and $\eta_{g}$ respectively, electrical power $P_{\text {elec }}$ consumed or regenerated by the train is estimated from the mechanical power by Eq. (6). Table I tabulates values of coefficients and variables used here to calculate $P_{\text {elec }}$ of Train\#1 and Train\#2 (e.g. ETR 600 electro train [12]) as shown in Fig. 4.

$$
P_{\text {elec }}=\left\{\begin{array}{l}
\left(F_{t r} \cdot v\right) /\left(\eta_{c} \cdot \eta_{m} \cdot \eta_{g}\right) \\
\left(F_{t r} \cdot v\right) \cdot\left(\eta_{c} \cdot \eta_{m} \cdot \eta_{g}\right)
\end{array}\right.
$$

TABLE I. VAlues of VARIABles for Train POWER CALCULATION

\begin{tabular}{|c|c|c|c|}
\hline Term & Value & Term & Value \\
\hline$M_{s}$ & $3.87 \times 10^{5} \mathrm{~kg}$ & $c_{r r}$ & 0.002 \\
\hline$M_{P}$ & $0.34 \times 10^{5} \mathrm{~kg}$ & $c_{a}$ & 0.5 \\
\hline$\lambda_{r}$ & 0.08 & $\rho_{a}$ & $1.225 \mathrm{~kg} / \mathrm{m}^{3}$ \\
\hline$A_{F}$ & $10 \mathrm{~m}^{2}$ & $\eta_{c}$ & 0.9 \\
\hline$g$ & $9.81 \mathrm{~N} / \mathrm{kg}$ & $\eta_{m}$ & 0.9 \\
\hline$\alpha$ & 0 radians & $\eta_{g}$ & 0.96 \\
\hline
\end{tabular}

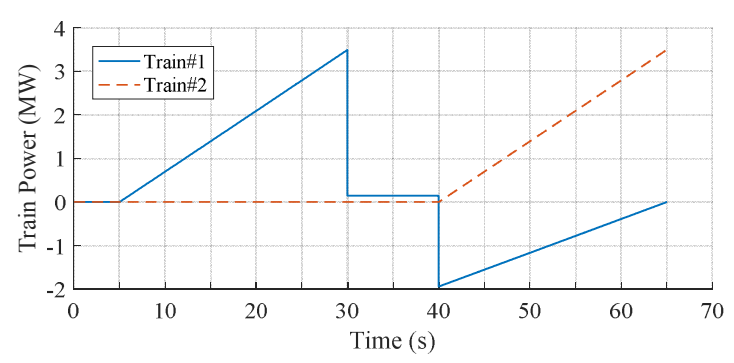

Fig. 4. Electrical power (MW) consumed (+ve) or regenerated (-ve) by two trains under simulation.

\section{Modelling OF RaIlWAy POWER SupPly System}

Four simulation models of railway power supply systems are developed for the presumed scenarios, i.e. Two USS + One Train (TUOT), Two USS + Two Trains (TUTT), Two RSS + One Train (TROT), and Two RSS + Two Trains (TRTT). Due to the similarity between different models, this section selects TUTT and TROT scenarios to detail the modelling of main components of DC railway systems, i.e. substations, trains and variable resistors of OHL sections, and describes the method of simulating power exchange between $\mathrm{AC}$ and DC sides.

\section{A. Simulation Model for TUTT Scenario}

The $3 \mathrm{kV}$ DC railway line between Pisa and Collesalvetti is currently supplied by two USS. The DC voltage provided by the USS is estimated to be around $3.7 \mathrm{kV}$ based on pantograph voltages $V_{\text {pan }}$ measured at times of no traffic along the line [12]. Fig. 5 shows the railway power supply system model developed in Simulink for TUTT scenario. Assuming USS to supply fixed DC voltage, each USS is modelled by a $3.7 \mathrm{kV}$ DC voltage source connected in series with a resistor which represents the internal resistance of USS when converting $\mathrm{AC}$ to $\mathrm{DC}$, and a diode which prevents the braking current from passing through USS [9]. Two trains are modelled by blocks of "Train\#1 Mdl" and "Train\#2 Mdl" respectively within which a controlled current source (CSS) is connected with a DC bus model [16]; the latter switches the braking resistance based on activation and shutdown voltages (i.e. $3.8 \mathrm{kV}$ and $3.75 \mathrm{kV}$ adopted here) so as to avoid $V_{\text {pan }}$ exceeding the over-voltage limit. The input signal of CSS driven by the current $I_{T}$ absorbed or regenerated by, e.g. Train\#1 is determined from $V_{\text {pan }}$ measured across "Train\#1 $M d l$ " block combined with $P_{\text {elec }}$ calculated by "Train\#1 Info" block based on Eqs. (1)-(6):

$$
I_{T}=P_{\text {elec }} / V_{\text {pan }}
$$

The $20 \mathrm{~km}$ line is split by two trains into three sections, the resistance of each section varying with the train movement. The length of each section is calculated from train positions and then multiplied by a DC resistance of $0.17 \Omega$ per $\mathrm{km}$ [12] 

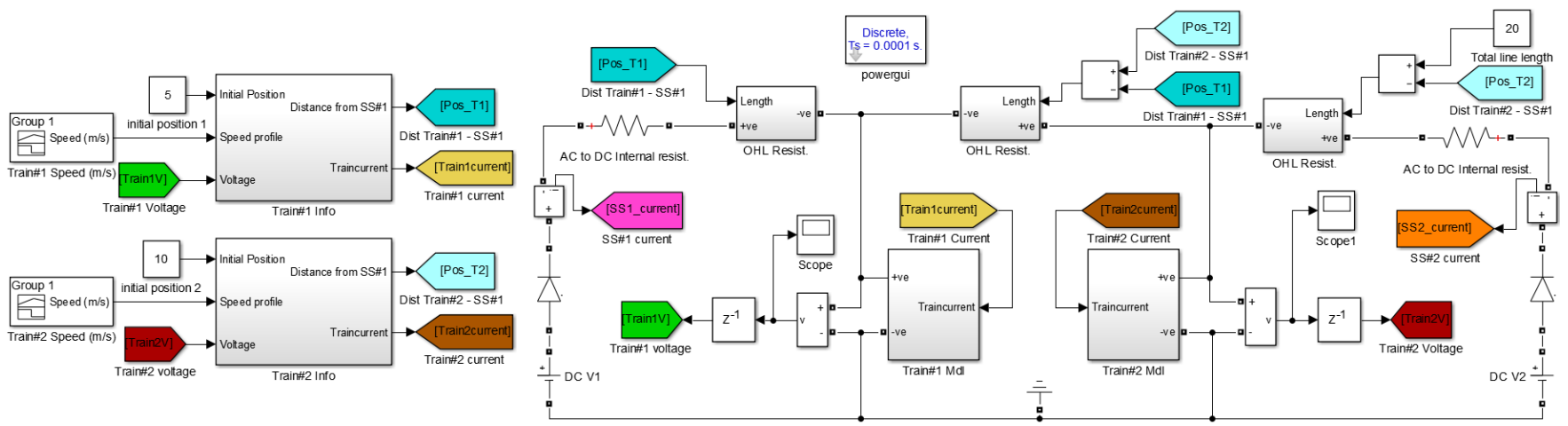

Fig. 5. A DC railway power supply system model developed for TUTT scenario in Simulink.
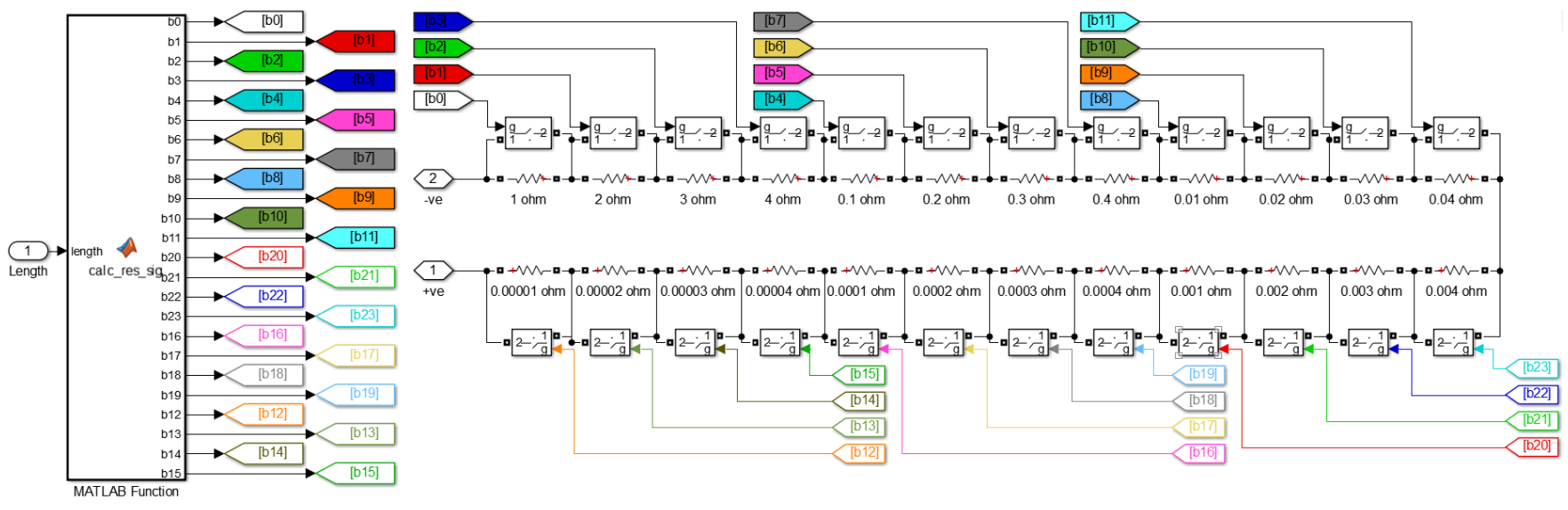

Fig. 6. The modelling of variable resistance of an OHL section by "OHL Resist." block.

to estimate the OHL section resistance. This is implemented in "OHL Resist." block which switches the series connected resistors ranging from $1-4 \Omega$ to $10-40 \mu \Omega$ to achieve the estimated value with an accuracy of $10 \mu \Omega$, as shown in Fig. 6. The simulated changes of resistance of the three OHL sections with train movements presumed in Fig. 2 are plotted in Fig. 7.

The electrical power supplied from the AC side to the DC system via each USS is calculated as the product of $3.7 \mathrm{kV}$ and the simulated value of current generated from each DC voltage source.

\section{B. Simulation Model for TROT Scenario}

The Simulink model of a single train (e.g. Train\#1) moving along the railway line supplied by two RSS is shown in Fig. 8. Compared to the USS based railway system model in Fig. 7, a resistor of $1 \Omega$ is additionally connected in parallel to each branch where the DC voltage source and diode are located, simulating the role of RSS that enables the braking current to be fed back to the $\mathrm{AC}$ side. In addition, when $V_{\text {pan }}$ of Train\#1 which absorbs current is smaller than $3.7 \mathrm{kV}$, the resistors representing the internal resistances of RSS when rectifying $\mathrm{AC}$ to $\mathrm{DC}$ are active; otherwise, they are shorted by closing their parallel connected switches.

Though the internal resistances of RSS when inverting DC to $\mathrm{AC}$ are not added into the power supply system model, they are considered in the calculation of braking power fed-backto the AC sides, as plotted in Fig. 9. Since the voltage across the $1 \Omega$ resistor parallel connected to the DC voltage source is fixed at $3.7 \mathrm{kV}$, the current passing through the $1 \Omega$ resistor is always $3.7 \mathrm{kA}$ which will be supplied completely by the DC voltage source at times of train consuming power. Therefore, during braking, the braking current fed-back-to the $1 \Omega$ resistor equals the drop from $3.7 \mathrm{kA}$ to the current generated from the $\mathrm{DC}$ voltage source. Then the voltage drop across the internal resistance of RSS when converting DC to AC is computed and deducted from $3.7 \mathrm{kV}$ so as to simulate the power losses at RSS. When the train is consuming power, the rise of the current generated from the DC voltage source above $3.7 \mathrm{kA}$ reflects the current supplied from the AC side via RSS to the DC system.

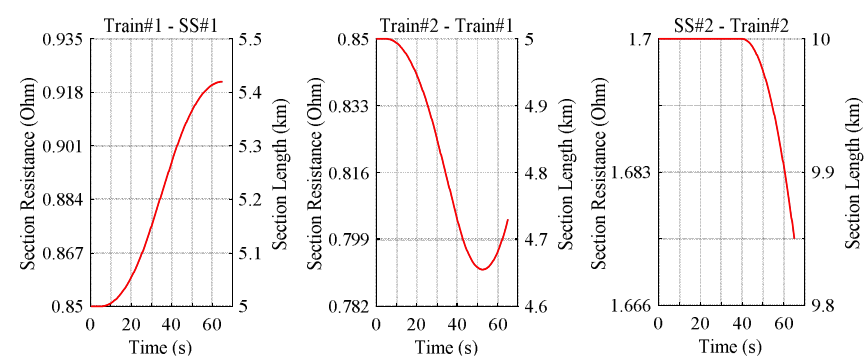

Fig. 7. Resistances of three OHL sections varying with train movements.

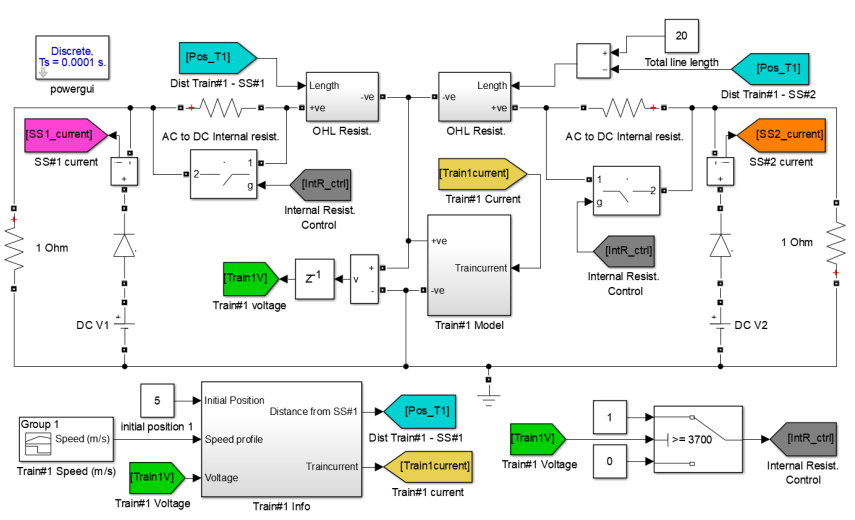

Fig. 8. A DC railway system model developed for TROT scenario. 


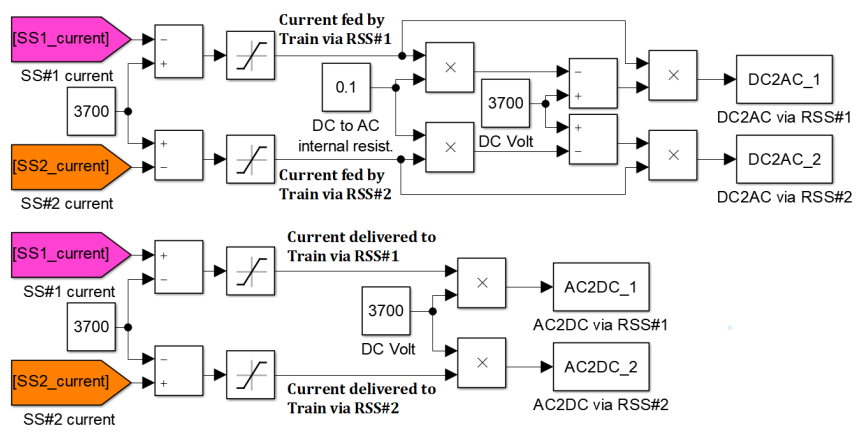

Fig. 9. Calculation of power exchange between AC and DC sides via RSS.

\section{RESUlTS AND DISCUSSION}

This section implements the simulation of the railway power supply system models developed in Section III. The simulated $V_{\text {pan }}$ and power exchange between $\mathrm{AC}$ and $\mathrm{DC}$ sides in different scenarios are analysed to illustrate the model effectiveness and demonstrate the recovery of braking energy enabled by synchronised train operation and RSS.

\section{A. TUOT Scenario (Two USS + One Train)}

Fig. 10 shows $V_{\text {pan }}$ of a single train (i.e. Train\#1) moving along a railway line supplied by two USS. The power supplied by AC sides via USS and consumptions of Train\#1 are plotted in Fig. 11. With the Train\#1 consumption increasing before 30 s, growth of current delivered from USS to Train\#1 increase the voltage drops across internal resistors and OHL resistors which reduce $V_{\text {pan }}$ of Train\#1 (Fig. 10). These also increase transmission losses which are reflected by the gaps between total power supplied by USS and train consumption as shown in Fig. 11b. Furthermore, Fig. 11a shows that USS\#1 supplies more power to Train\#1 than USS\#2 due to a shorter distance from Train\#1 to USS\#1.

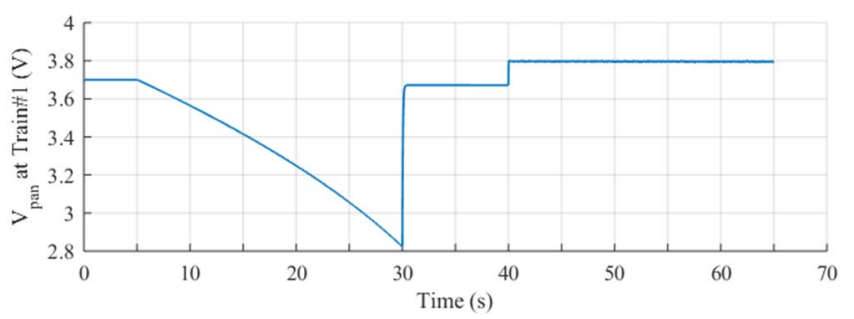

Fig. 10. $V_{\text {pan }}$ of Train\#1 in TUOT scenario.
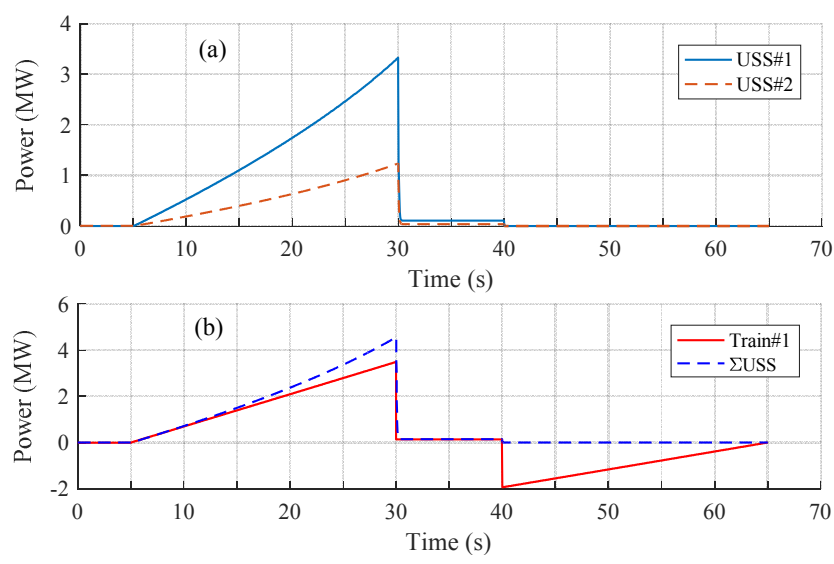

Fig. 11. (a) Power supplied by AC sides via each USS and (b) total power supplied by USS and power consumption of Train\#1 in TUOT scenario.
When Train\#1 brakes after $40 \mathrm{~s}$, since there is neither a RSS nor a neighbouring train that could recover the braking power in this scenario, the braking current injected into OHL raises $V_{\text {pan }}$ to a pre-specified value (i.e. the activation voltage of $3.8 \mathrm{kV}$ ), which activates the braking resistor to avoid $V_{\text {pan }}$ exceeding $3.8 \mathrm{kV}$ as shown in Fig. 10. The regenerated energy is then dissipated as heat in the braking resistor.

\section{B. TROT Scenario (Two RSS + One Train)}

Fig. 12 shows $V_{\text {pan }}$ of Train\#1 supplied by two RSS. The power supplied by (+ve) or fed-back-to (-ve) AC sides via the RSS and that consumed (+ve) or regenerated (-ve) by Train\#1 are plotted in Fig. 13. Since only Train\#1 consumes power before $40 \mathrm{~s}$, different scenarios have the same profiles of $V_{\text {pan }}$ at Train\#1 and power flows between SS and Train\#1 over this period. Therefore, $V_{\text {pan }}$ and power exchange beyond 40 s will be specifically considered in the following analysis.

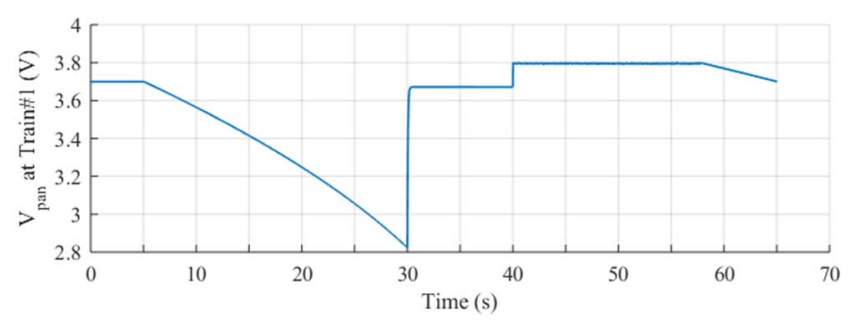

Fig. 12. $V_{\text {pan }}$ at Train\#1 in TROT scenario.
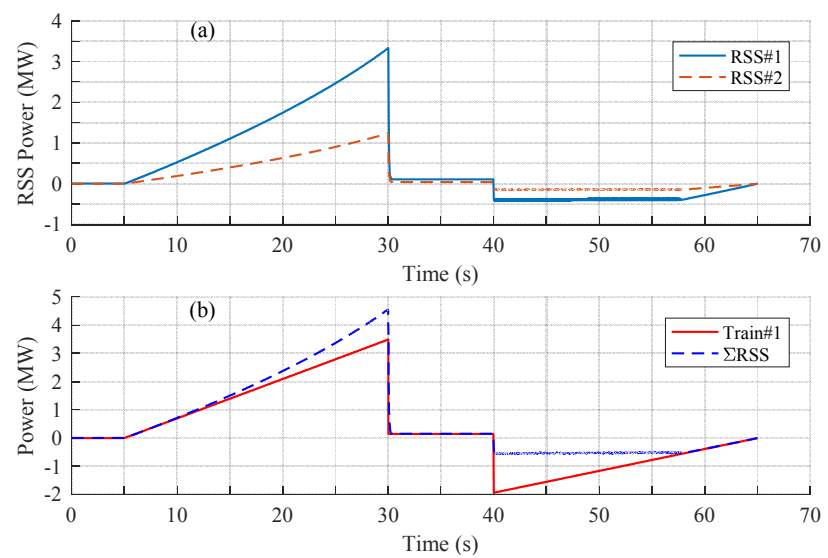

Fig. 13. (a) Power supplied by (+ve) or fed-back-to (-ve) AC sides via each RSS and (b) aggregated power exchange via two RSS against power consumed (+ve) or regenerated (-ve) by Train\#1 in TROT scenario.

Over the period from 40 s to around $57.7 \mathrm{~s}$, the gap between the braking power of Train\#1 and the aggregated power fedto AC sides (Fig. 13b) indicates that part of the braking energy is recovered while the surplus is dissipated in the braking resistor. Otherwise, the excessive current flowing to RSS would raise the voltage across OHL resistors, leading to exceedance of $V_{\text {pan }}$ over the limit of $3.8 \mathrm{kV}$. Beyond $57.7 \mathrm{~s}$, $V_{\text {pan }}$ gradually decreases from $3.8 \mathrm{kV}$ to $3.7 \mathrm{kV}$ (Fig. 12) and all of the braking energy is transferred to RSS. In addition, Fig. 13a shows that more braking power is delivered to RSS\#1 which is closer to Train\#1.

\section{TUTT Scenario (Two USS + Two Trains)}

Fig. 14 shows $V_{\text {pan }}$ at Train\#1 and Train\#2 supplied by two USS. It is noted that the deceleration of Train\#1 is synchronised with the acceleration of Train $\# 2$ over $40 \mathrm{~s}-65 \mathrm{~s}$. The power supplied by AC sides via USS and the aggregated train power are plotted in Fig. 15. 


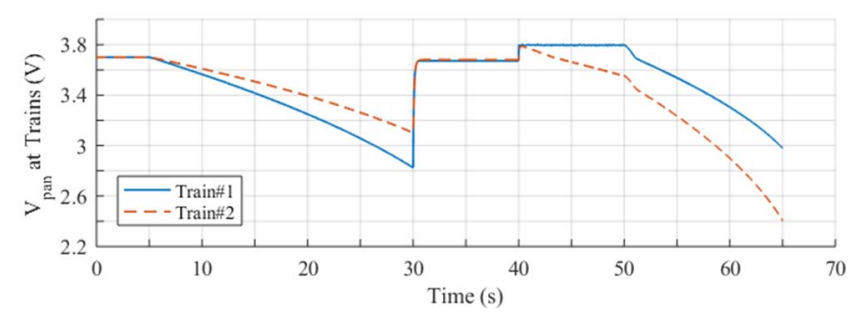

Fig. 14. $V_{\text {pan }}$ at Train\#1 and Train\#2 in TUTT scenario.
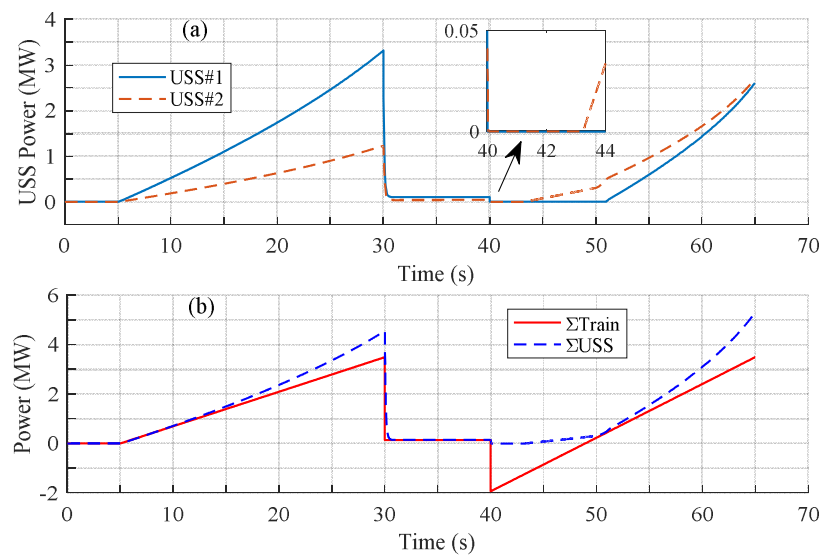

Fig. 15. (a) Power supplied by AC sides via each USS and (b) total power supplied by AC sides via two USS and aggregated power of the two trains in TUTT scenario.

Over the period from 40 s to around 43 s, neither USS supply power for the acceleration of Train\#2 as shown in Fig. $15 \mathrm{a}$, revealing that Train\#2 consumption is fully supported by the braking energy regenerated from Train\#1. Furthermore, the braking resistor of Train\#1 is activated to dissipate the excess regenerated energy, maintaining $V_{\text {pan }}$ at $3.8 \mathrm{kV}$ (Fig. 14). Then USS\#2 starts to export while the output of USS\#1 remains at zero prior to around $51 \mathrm{~s}$. This is because $V_{\text {pan }}$ at Train\#2, closer to USS\#2, drops below the supplied DC voltage of $3.7 \mathrm{kV}$ while $V_{\text {pan }}$ at Train\#1, closer to USS\#1, still exceeds $3.7 \mathrm{kV}$. In addition, the export of USS\#2 over $43 \mathrm{~s}-$ 49 s means that, in spite of Train\#2 consumption being smaller than the braking power of Train\#1 over this period (Fig. 4), only part of Train\#2 consumption is from the braking power and the surplus braking energy is dissipated in the braking resistor so as to avoid violation of the over-voltage limit. Beyond $51 \mathrm{~s}, V_{\text {pan }}$ at Train\#1 falls below $3.7 \mathrm{kV}$ and USS\#1 begins to deliver power to Train\#2.

\section{TRTT Scenario (Two RSS + Two Trains)}

Fig. 16 shows $V_{\text {pan }}$ at Train\#1 and Train\#2 supplied by two RSS. The power supplied by (+ve) or fed-back-to (-ve) AC sides via RSS and aggregated power of the two trains are plotted in Fig. 17. Fig. 17a shows that over the period from $40 \mathrm{~s}$ to around $43 \mathrm{~s}$, the power fed-back-to the AC side via RSS\#1 almost remains constant while the power fed back via RSS\#2 decreases due to part of the braking current flowing to RSS\#2 being absorbed by Train\#2. Then RSS\#2 begins to supply power to Train\#2 while RSS\#1 consistently provides the path for the delivery of the braking power of Train\#1 prior to around $51 \mathrm{~s}$.

Fig. 16 shows that $V_{\text {pan }}$ at Train\#1 is kept at $3.8 \mathrm{kV}$ (i.e. the activation voltage of braking resistor) from $40 \mathrm{~s}$ to about $47.5 \mathrm{~s}$, meaning that part of the regenerated power of Train\#1 is dissipated in the braking resistor to avoid exceeding the over-

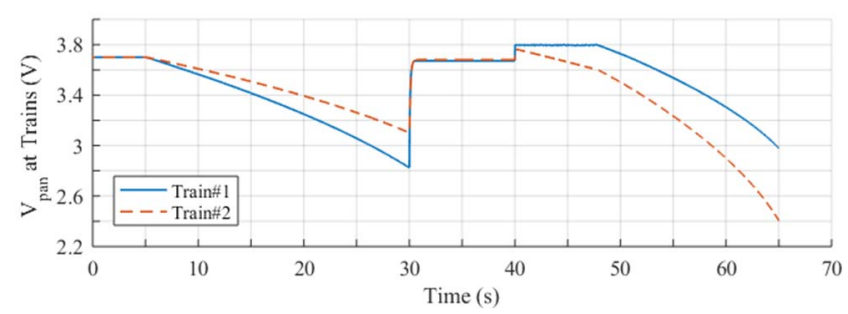

Fig. 16. $V_{\text {pan }}$ at Train\#1 and Train\#2 in TRTT scenario.
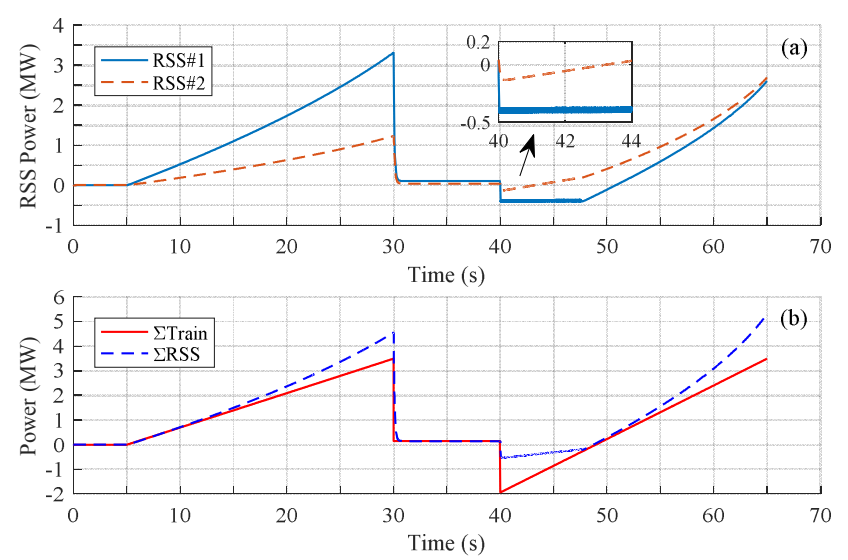

Fig. 17. (a) Power supplied by (+ve) and fed-back-to (-ve) AC sides via each RSS and (b) aggregated power exchange via two RSS against aggregated power of trains in TRTT scenario.

voltage limit. When $V_{\text {pan }}$ at Train\#1 reduces from $3.8 \mathrm{kV}$ to $3.7 \mathrm{kV}$, all of the braking energy of Train\#1 is recovered by RSS\#1 and Train\#2. Beyond 51s, with $V_{\text {pan }}$ of Train\#1 falling below $3.7 \mathrm{kV}$, RSS\#1 along with Train\#1 and RSS\#2 supplies power to Train\#2.

\section{E. Energy Saving by Braking Energy Recovery}

The simulation results show that braking energy can be recovered by surrounding accelerating trains and RSS subject to $V_{\text {pan }}$. Table II lists the total energy exchange $(\mathrm{kWh})$ via substations, i.e. energy supplied by and fed-to AC sides in different scenarios. Using the TUOT scenario as a benchmark, the energy saving achieved by braking energy recovery in the TROT scenario is determined as the sum of the energy fedback-to AC sides and the reduction of the energy supplied by $\mathrm{AC}$ sides. In this way, energy losses in braking resistors, $\mathrm{OHL}$ resistors and internal resistors of substations are considered.

To quantify energy savings in TUTT and TRTT scenarios, an additional TUOT scenario is simulated where only Train\#2 moves along the line; volumes of the energy supplied by AC sides in two TUOT scenarios are then added up as the total energy required to support the two trains in a particular scenario (i.e. denoted by TUOT2) where the braking energy could not be recovered.

TABLE II. TOTAL ENERGY EXCHANGE (KWH) BETWEEN AC AND DC SiDES AND ASSOCIATED ENERGY SAVING (KWH) ACHIEVED BY THE BRAKING ENERGY RECOVERY IN DIFFERENT SCENARIOS.

\begin{tabular}{|c|c|c|c|}
\hline Scenario & $\begin{array}{c}\text { Energy (kWh) } \\
\text { from AC to DC }\end{array}$ & $\begin{array}{c}\text { Energy (kWh) } \\
\text { from DC to AC }\end{array}$ & $\begin{array}{c}\text { Energy } \\
\text { Saving (kWh) }\end{array}$ \\
\hline TUOT & 14.6 & 0 & 0 \\
\hline TROT & 14.6 & 3.2 & 3.2 \\
\hline TUOT2 & 29.9 & 0 & 0 \\
\hline TUTT & 25.1 & 0 & 4.8 \\
\hline TRTT & 25.1 & 1.1 & 5.9 \\
\hline
\end{tabular}


Given that the braking energy of Train\#1 is about $12.2 \mathrm{kWh}$ in the scenarios presumed here, Table II shows that around $3.2 \mathrm{kWh}$ (i.e. $26.2 \%$ ) and $4.8 \mathrm{kWh}$ (i.e. $39.3 \%$ ) of the braking energy are recovered by the RSS in TROT scenario and by the acceleration of Train\#2 in TUTT scenario respectively. In TRTT scenario, $81.4 \%$ of the energy saving (i.e. $4.8 \mathrm{kWh}$ out of $5.9 \mathrm{kWh}$ ) is achieved through synchronised operation of the two trains.

\section{CONCLUSIONS AND FUTURE WORK}

An efficient recovery of regenerative braking energy is one of the strategies to improve the energy efficiency of DC railway power supply systems. An effective way is to upgrade the existing USS to RSS that provides a path via which the braking energy of trains can be fed back to the AC sides. The high cost of investment on RSS requires the cost-benefit analysis of the deployment of RSS, driving the need for evaluation of energy savings. This paper has developed simulation models of $3 \mathrm{kV}$ DC railway systems in Simulink to estimate power exchange between $\mathrm{AC}$ and DC sides. The simulation models have been tested based on four presumed scenarios where one/two trains move along a $20 \mathrm{~km}$ railway line supplied by two USS/RSS. The effectiveness of the models developed here is assessed by analysing the simulated pantograph voltages and power flows within the railway system in each scenario. The synchronised operation of trains and the deployment of RSS show their capability of recovering the braking energy subject to pantograph voltage.

Building on the present work, the developed models should be compared to practical operation of trains to evaluate energy savings achieved by RSS. Furthermore, impacts of different factors (e.g. number and positions of trains and the extent of synchronisation of their deceleration and acceleration) on the braking energy recovery will require to be assessed. Moreover, a high-fidelity railway system model may be developed to analyse the effects of injecting the regenerated power into the AC side via RSS on the local network.

\section{ACKNOWLEDGMENT}

The research was developed under the 16ENG04 MyRailS Project which received funding from the EMPIR programme co-finance by the Participating States and from the European Union's Horizon 2020 Research and Innovation Programme.

\section{REFERENCES}

[1] Moving towards Sustainable Mobility - a Strategy for 2030 and beyond for the European Railway Sector, International Union of Railways (UIC), Summary Rep., Paris, 2012.

[2] M. Popescu and A. Bitoleanu, "A review of the energy efficiency improvement in DC railway systems," Energies, vol. 12, no. 6, paper 1092, pp. 1-25, 2019.

[3] M. Khodaparastan, A. Mohamed, and W. Brandauer, "Recuperation of regenerative braking energy in electric rail transit systems," IEEE Trans. Intell. Transp. Syst., vol. 20, no. 8, pp. 2831-2847, 2019.

[4] A. Nasri, M. Moghadam, and H. Mokhtari, "Timetable optimization for maximum usage of regenerative energy of braking in electrical railway systems," Int. Symp. Power Electronics, Electrical Drives, Automation and Motion, SPEEDAM, 2010.

[5] M. Ceraolo, G. Lutzemberger, E. Meli, L. Pugi, A. Rindi, and G. Pancari, "Energy storage systems to exploit regenerative braking in DC railway systems: different approaches to improve efficiency of modern high-speed trains," J. Energy Storage, vol. 16, pp. 269-279, 2018.

[6] D. Cornic, "Efficient recovery of braking energy through a reversible dc substation," Electrical Systems for Aircraft, Railway and Ship Propulsion, 2010.

[7] A. Gonzalez-Gil, R. Palacin, and P. Batty, "Sustainable urban rail systems: strategies and technologies for optimal management of regenerative braking energy," Energy Conversion and Management, vol. 75, pp. 374-388, 2013.

[8] F. Mao, Z. Mao, and K. Yu, "The modelling and simulation of DC traction power supply network for urban rail transit based on Simulink,' J. Physics: Conference Series, vol. 1087, pp. 1-6, 2018

[9] H. Alnuman, D. Gladwin, and M. Foster, "Electrical modelling of a DC railway system with multiple trains," Energies, vol. 11, no. 11, paper $3211,2018$.

[10] M. Saleh, O. Dutta, Y. Esa, and A. Mohamed, "Quantitative analysis of regenerative energy in electric rail traction systems," CUNY Academic Works, 2017.

[11] MATLAB Release 2016a, Natick, MA, USA.

[12] G. Crotti, A. Femine, D. Gallo, D. Giordano, C. Landi, M. Luiso, A. Mariscotti, and P. Roccato, "Pantograph-to-OHL arc: conducted effects in DC railway supply system," IEEE Trans. Instrum. Meas., vol. 68, no. 10, pp. 3861-3870, 2019.

[13] T. Kulworawanichpong, "Multi-train modelling and simulation integrated with traction supply solver using simplified NewtonRaphson method," Journal of Modern Transportation, vol. 23, no. 4, pp. 241-251, 2015.

[14] M. Chymera and C.J. Goodman, "Overview of electric railway systems and the calculation of train performance," IET Professional Development Course on Electric Traction Systems, pp. 1-18, 2012.

[15] N. Zhao, L. Chen, Z. Tian, C. Roberts, S. Hillmansen, and J. Lv, "Field test of train trajectory optimisation on a metro line," IET Intelligent Transport Systems, vol. 11, no. 5, pp. 273-281, 2017.

[16] The MathWorks Inc., DC Bus - Implement DC Bus Model that includes Resistive Braking Chopper, 2019. [Online]. Available: https://uk.mathworks.com/help/physmod/sps/powersys/ref/dcbus.html 